\title{
Correlation of the Stature to Forearm Length in the Young Adults of Western Indian Population.
}

\author{
Suryabhan S. Dongre ${ }^{1}$, Ravindra B. Deokar ${ }^{2}$, Sachin S. Patil ${ }^{3}$ \\ ${ }^{1}$ Associate Professor \& Head, Department of Agadtantra, APM's AyurvedMahavidyalaya, Sion, Mumbai, 400022, \\ Maharashtra, India, ${ }^{2}$ Professor (Additional), Department of Forensic Medicine and Toxicology, Seth G.S. Medical \\ College \& KEM Hospital, Mumbai, 400 012, Maharashtra, India, ${ }^{3}$ Associate Professor, Department of Forensic \\ Medicine and Toxicology, Seth G.S. Medical College \& KEM Hospital, Mumbai, 400 012, Maharashtra, India
}

\begin{abstract}
Introduction: Forensic anthropometry dealing with the application of anthropometric measurements of human individual for the purposes of the identification of human remains. Inter and intra population variations can be observed in relation to anthropometric measurements due to factors such as genetic makeup, age, gender and ethnicity and help in the identification of individual in criminal investigations.
\end{abstract}

Method: This is cross sectional study using young adult students of age group 17 to 24 years. Participants enrolled after due consent and stature(S) and forearm length (FAL) were measured using standard anthropometric techniques. SPSS statistical package used to calculate Pearson's coefficients of correlation and regression equations between stature and the anthropometric variables.

Results: There were total 255 participants including $54(21.18 \%)$ males and $201(78.82 \%)$ females. Regression equation for estimation of stature from right forearm length is $\mathrm{S}=1.4111 \mathrm{Rt} F A L+126.72$, and from left forearm length is $\mathrm{S}=1.3774 \mathrm{Lt} \mathrm{FAL}+128.39$. There were strong positive correlations between height and forearm lengths in all regressions $(r>0.9 ; \mathrm{p}<0.0001)$.

Conclusions: The proposed regression equations based on forearm length presented here will simplify the task of stature estimation for adults in clinical forensic medicine or as aids to the identification in criminal investigation in endogenous population. The left forearm length is more accurate in estimating the stature of young adults of western Indian population.

Keywords: Clinical Forensic Medicine, Identification, anthropometry, regression, Height.

\section{Introduction}

Anthropometry refers to the systematic measurement of the physical properties of the human

\section{Corresponding Author:}

Dr. Ravindra Baliram Deokar MD[FM], LLB, LLM (Human Rights), Professor (Additional), Department of Forensic Medicine \& Toxicology, Seth G.S. Medical College \& KEM Hospital, Mumbai, 400 012, Maharashtra, India e-mail: ravideo80@gmail.com

Contact Number: +919869741117/9423016325 body, mainly dimensional descriptors of body size and shape. The science dealing with the study of systemic measurements of the human individual is called as Anthropometry. ${ }^{1}$ Forensic anthropometry dealing with the application of anthropometric measurements of human individual for the purposes of the identification of human remains. Other medicolegal facts can be determined such as establishing the age at the time of death, sex, stature, body type (somatotype) and any other distinguishing characteristics based on physical and skeletal measurements helping in identification of the deceased individual. ${ }^{2,3}$

In the field of scientific research in Clinical Forensic Medicine, various anthropometric parameters likearm 
span, biacromial shoulder width, hand length, forearm length, foot length and breadth, etc. may be used to predict the stature i.e. individual's height. ${ }^{4,5}$ Various studies conducted to predict stature using various parts of human body and skeleton. ${ }^{6}$ Forearm length can be helpful in predicting the individual's stature in mutilated bodies with remains involving upper limbs. ${ }^{7}$ The stature can be predicted on the basis of forearm length and can be estimated using various regression equations. ${ }^{8,9}$

Several researchers studied relation between stature and upper limb segments measurements such as arm span, Biacromial width, arm length, forearm length, hand length in different populations. ${ }^{5-15}$ Many authors had been demonstrated strong relationship between stature and forearm length. ${ }^{8,9,14-16}$ Due to racial and ethnic variations in Indian population, the region-wise, population-based anthropometric studies are necessary in India. This study was undertaken to compare the stature (S) to forearm length (FAL) in western Indian population involving young adults to formulate a regression equation and to determine correlation between Stature and Forearm length.

\section{Materials and Method}

Study design and Procedure: This was a cross sectional study conducted in the Department of Agadtantra, APM's Ayurved Mavidyalaya, Sion, Mumbai, Maharashtra, India after institutional ethical committee approval. The study was conducted over a period of 2 years, from June 2015 to June 2017. Most of the students of this institution in this period, those fulfilling the inclusion criteria and giving voluntary consent to involve in the study were considered as the subjects for this study.

Study Participants: By simple random sampling, two hundred fifty-five students (54 males \& 201 females) of this institution with ages between 17 to 24 years were included in this study. The written informed consent was taken from all subjects. The students of this specific region of ancestral origin were the target population. All subjects were measured approximately at the same time in the morning hours. Subjects with limb or vertebral column deformities, injury, fracture or those who underwent an operative procedure on spine/extremities, or abnormal gait were excluded from the study. All the measurements were tabulated and subjected to statistical analysis.

Measurements: Stature, forearm lengths of right (Rt) and left (Lt) forearms of the subjects were measured. The unit used throughout the study is centimeters. All observations were recorded in a predesigned proforma. Measurements were taken by the first author to avoid inter-observer bias

Stature (S): Stature (S) was measured with a stadiometer with movable headboard. It was taken from the vertex to the floor with the person standing barefoot in the anatomical position and with the head in Frankfurt horizontal plane (i.e. the line joining the inferior margin of the orbit and upper margin of external auditory meatus). The subjects were asked to stand on a horizontal even surface against a vertical plane in an erect posture, with feet in close approximation, hands by their side. The shoulders and buttocks were touching the vertical plane.

Forearm Length (FAL): The subject asked to stand erect with back to the wall, both arms abducted to $90^{\circ}$. For taking measurements, the forearm on each side is flexed at $90^{\circ}$ at elbow joint with extended wrist and the palms facing upwards. The forearm \& hand is supported on a flat adjustable top of a table for measurement purposes. Forearm length was measured with a flexible steel tape from the tip of the olecranon process to the point between radius \& ulnar tuberosity. Readings were taken to the nearest $0.1 \mathrm{~cm}$.

Statistical Analysis: The data obtained were analyzed statistically using SPSS (Statistical Package for Social Sciences) version 16.0 computer software (SPSS, Inc., Chicago, IL).

\section{Results}

There were total 255 participants including 54 $(21.18 \%)$ males and $201(78.82 \%)$ females. The descriptive statistics for stature and forearm length are shown in Table 1. 
Table No. 1: Descriptive Statistics of stature (S) and Forearm length (FAL) of whole sample.

\begin{tabular}{|l|c|c|c|c|c|c|}
\hline Parameter & Minimum & Maximum & Mean & Std. Deviation & N & SEM \\
\hline Stature(S) & 145.0 & 179.0 & 161.172 & 6.7755 & 255 & 0.4239 \\
\hline Right Forearm Length (Rt FAL) & 12.5 & 35.7 & 24.4 & 4.704 & 255 & 0.29 \\
\hline Left Forearm Length (Lt FAL) & 11.9 & 35.8 & 23.8 & 4.858 & 255 & 0.30 \\
\hline Average Forearm Length (Av FAL) & 12.2 & 35.75 & 24.1 & 4.774 & 255 & 0.30 \\
\hline
\end{tabular}

The differences between male and female group were compared using unpaired t-test (S, Rt FAL, Lt FAL, Av FAL). Stature (S) of the participants ranged from 152.0 to $179.0 \mathrm{~cm}$ in males and 145.0 to 175.0 $\mathrm{cm}$ in females. Mean stature in males $(167.8 \mathrm{~cm})$ was significantly larger $(\mathrm{p}<0.001)$ than that in females $(159.4 \mathrm{~cm})$. Right Forearm (Rt FAL) of the participants ranged from 17.6 to $35.7 \mathrm{~cm}$ in males and 12.5 to 34.4 $\mathrm{cm}$ in females. Mean Right forearm in males $(28.9 \mathrm{~cm})$ was significantly larger $(\mathrm{p}<0.001)$ than that in females
$(23.2 \mathrm{~cm})$. Left Forearm (Lt FAL) of the participants ranged from 16.9 to $35.8 \mathrm{~cm}$ in males and 11.9 to 34.2 $\mathrm{cm}$ in females. Mean left forearm in males $(28.5 \mathrm{~cm})$ was significantly larger $(\mathrm{p}<0.001)$ than that in females $(22.5 \mathrm{~cm})$. Average Forearm (Lt FAL) of the participants ranged from 17.25 to $35.75 \mathrm{~cm}$ in males and 12.2 to 34.3 $\mathrm{cm}$ in females. Mean average forearm in males $(28.7 \mathrm{~cm})$ was significantly larger $(\mathrm{p}<0.001)$ than that in females $(22.9 \mathrm{~cm})$. Sex-wise descriptive statistics for stature and forearms length are shown in Table 2.

Table 2: Sex-wise descriptive statistics for Stature (S), Right Forearm length (Rt FAL), Left Forearm length (Lt FAL), Average Forearm length (Av FAL).

\begin{tabular}{|l|c|c|c|c|c|c|c|c|}
\hline \multirow{2}{*}{ Indicator } & \multicolumn{2}{|c|}{ Stature (S). } & \multicolumn{2}{c|}{$\begin{array}{c}\text { Right Forearm } \\
\text { Length (Rt FAL) }\end{array}$} & $\begin{array}{c}\text { Left Forearm Length } \\
\text { (Lt FAL) }\end{array}$ & $\begin{array}{c}\text { Average Forearm } \\
\text { Length (Av FAL) }\end{array}$ \\
\cline { 2 - 11 } & \multicolumn{2}{|c|}{ Sex } & \multicolumn{2}{|c|}{ Sex } & \multicolumn{2}{c|}{ Sex } & \multicolumn{2}{c|}{ Sex } \\
\cline { 2 - 10 } & F & M & F & M & F & M & F \\
\hline Count & 201 & 54 & 201 & 201 & 201 & 54 & 201 & 54 \\
\hline Minimum & 145.0 & 152.0 & 12.5 & 17.6 & 11.9 & 16.9 & 12.2 & 17.25 \\
\hline Maximum & 175.0 & 179.0 & 34.4 & 35.7 & 34.2 & 35.8 & 34.3 & 35.75 \\
\hline Mean & 159.4 & 167.8 & 23.2 & 28.9 & 22.5 & 28.5 & 22.9 & 28.7 \\
\hline Median & 159.0 & 168.0 & 22.9 & 29.5 & 22.3 & 29.1 & 22.6 & 29.1 \\
\hline Mode & 157.0 & 171.0 & 25.1 & 29.5 & 22.3 & 31.3 & 21.15 & 29.1 \\
\hline Standard Deviation & 5.9 & 5.9 & 4.12 & 3.99 & 4.20 & 4.17 & 4.15 & 4.07 \\
\hline Standard Error of Mean & 0.41 & 0.80 & 0.29 & 0.54 & 0.30 & 0.57 & 0.29 & 0.55 \\
\hline Percentile 05 & 150.0 & 156.0 & 16.50 & 20.50 & 16.10 & 19.90 & 16.25 & 20.30 \\
\hline Percentile 25 & 156.0 & 165.0 & 20.70 & 27.30 & 19.80 & 26.70 & 20.20 & 27.00 \\
\hline Percentile 75 & 164.0 & 171.4 & 26.20 & 31.60 & 25.40 & 31.30 & 25.65 & 31.40 \\
\hline Percentile 95 & 168.9 & 177.0 & 30.10 & 35.30 & 29.50 & 34.90 & 29.70 & 35.10 \\
\hline Percentile 99 & 172.0 & 179.0 & 32.40 & 35.70 & 31.60 & 35.80 & 32.00 & 35.75 \\
\hline
\end{tabular}

Scatter diagram and regression line plotted to show relationship for whole sample for estimation of stature from Right forearm, left forearm shown in fig. 01 to 02. 
Fig. 01: Relationship between stature and Right Forearm Length.

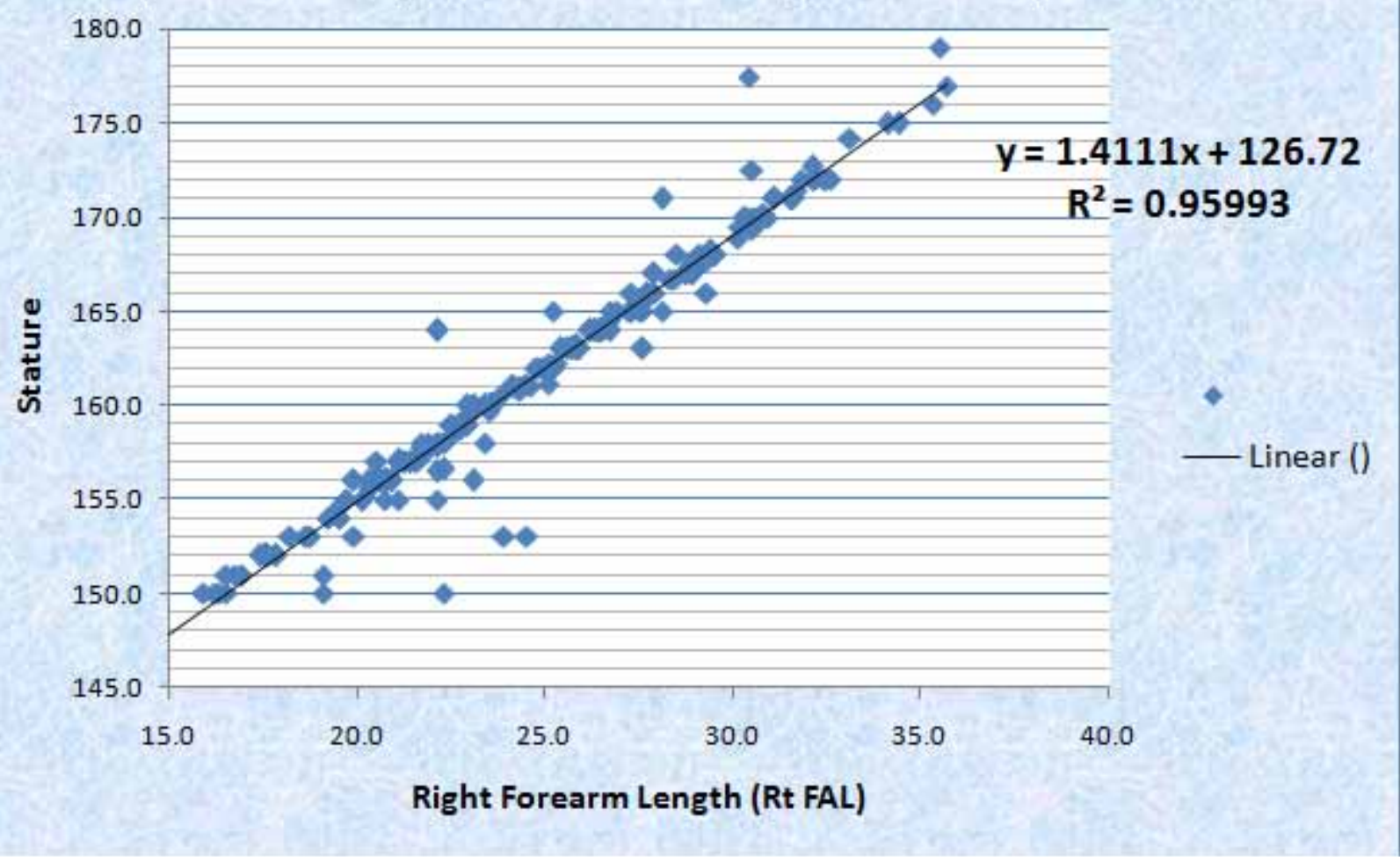

Figure 1: Scatter diagram and regression line showing relationship between stature and Right Forearm length. (All dimensions in Centimeters).

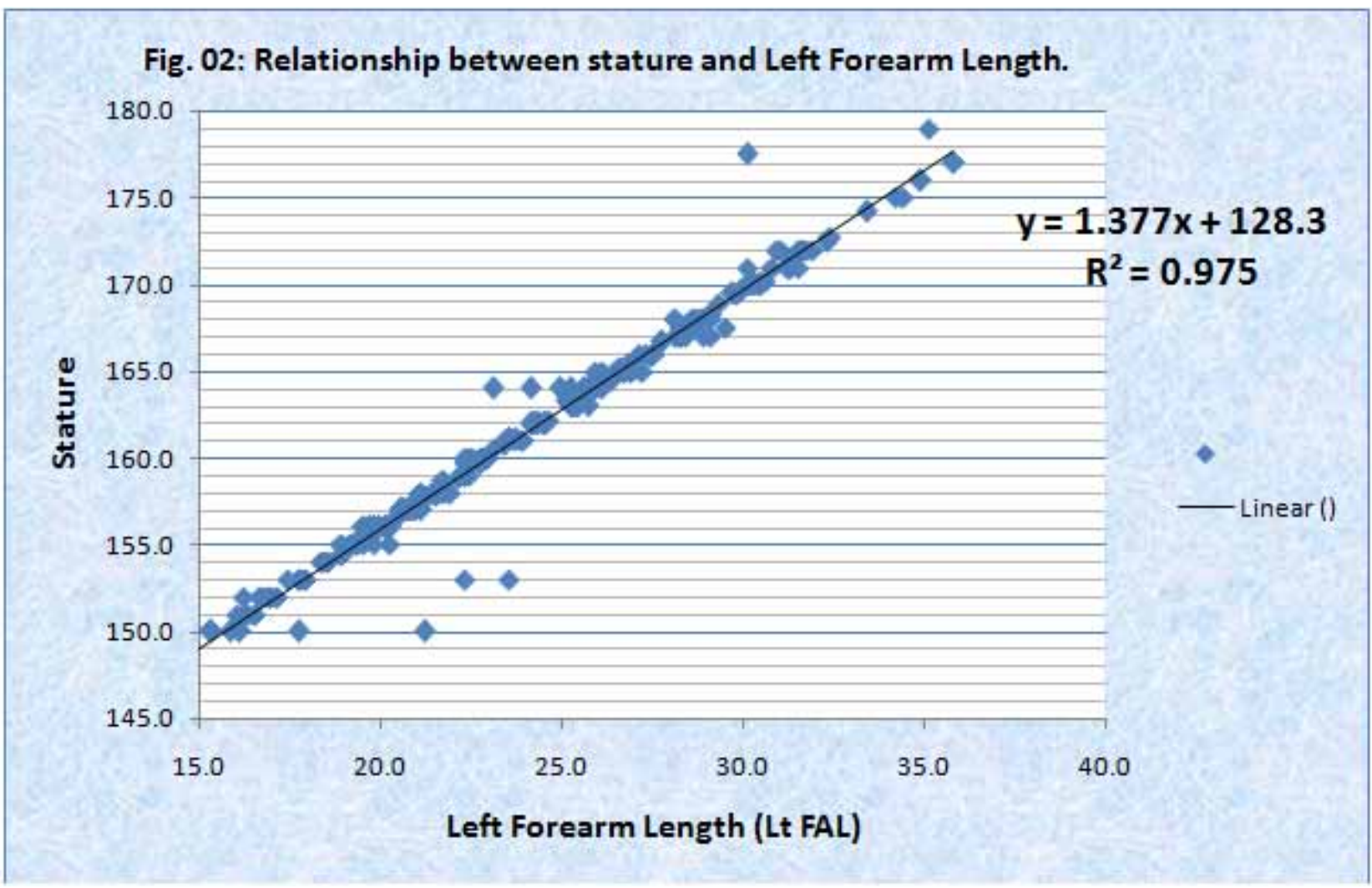

Figure 2: Scatter diagram and regression line showing relationship between stature and Left Forearm length. (All dimensions in Centimeters). 
Linear regression equations were derived for whole sample, for total males \& females separately for estimation of stature from right forearm length, left forearm length and average forearm length. The right arm length and left forearm length were used as the dependent variable to calculate the estimated stature.
The resulting linear regression equation in the form of $y=a x+b$ (where, ' $y$ ' is stature in centimeters; ' $x$ ' is actual forearm length in centimeters; ' $a$ ' is the slope of regression line and ' $b$ ' is the intercept of the regression line) were tabulated in table no. $\mathbf{0 3}$.

Table No. 03: Various Linear regression equations for stature with forearm lengths (Right, Left average in whole sample, male $\&$ females.

\begin{tabular}{|l|c|c|c|c|}
\hline Regression Group & Linear Regressions & Linear Regressions & $\mathbf{R}^{\mathbf{2}}$ & $\mathbf{R}$ \\
\hline $\begin{array}{l}\text { Stature with Right Forearm length (whole } \\
\text { Sample) }\end{array}$ & $\mathrm{y}=1.4111 \mathrm{x}+126.72$ & $\mathrm{~S}=1.4111 \mathrm{x}+126.72$ & 0.95993 & 0.979760 \\
\hline $\begin{array}{l}\text { Stature with Left Forearm length (whole } \\
\text { Sample) }\end{array}$ & $\mathrm{y}=1.3774 \mathrm{x}+128.39$ & $\mathrm{~S}=1.3774 \mathrm{x}+128.39$ & 0.97523 & 0.987537 \\
\hline $\begin{array}{l}\text { Stature with Average Forearm length (whole } \\
\text { Sample) }\end{array}$ & $\mathrm{y}=1.3982 \mathrm{x}+127.46$ & $\mathrm{~S}=1.3982$ AV FAL +127.46 & 0.97056 & 0.985170 \\
\hline Stature with Right Forearm length (Female) & $\mathrm{y}=1.3852 \mathrm{x}+127.26$ & $\mathrm{~S}(\mathrm{~F})=1.3852$ RT FAL (F)+127.26 & 0.94867 & 0.973997 \\
\hline Stature with Left Forearm length (Female) & $\mathrm{y}=1.3711 \mathrm{x}+128.52$ & $\mathrm{~S}(\mathrm{~F})=1.3711$ LT FAL (F)+128.52 & 0.96888 & 0.984317 \\
\hline Stature with Right Forearm length (Male) & $\mathrm{y}=1.4296 \mathrm{x}+126.42$ & $\mathrm{~S}(\mathrm{M})=1.4296 \mathrm{RT}$ FAL (M)+126.42 & 0.94067 & 0.969881 \\
\hline Stature with Left Forearm length (Male) & $\mathrm{y}=1.3817 \mathrm{x}+128.32$ & $\mathrm{~S}(\mathrm{M})=1.3817$ LT FAL (M)+128.32 & 0.95908 & 0.979326 \\
\hline $\begin{array}{l}\text { Stature with Average Forearm length } \\
\text { (Female) }\end{array}$ & $\mathrm{y}=1.3828 \mathrm{x}+127.78$ & $\mathrm{~S}(\mathrm{~F})=1.3828$ AV FAL (F)+127.78 & 0.96207 & 0.980852 \\
\hline Stature with Average Forearm length (Male) & $\mathrm{y}=1.4138 \mathrm{x}+127.14$ & $\mathrm{~S}(\mathrm{M})=1.4138$ AV FAL (M)+127.14 & 0.95583 & 0.977666 \\
\hline
\end{tabular}

Right Forearm length (Rt FAL) showed high positive value of correlation coefficient $(>0.9)$ which suggest a strong positive correlation between stature and Rt FAL [Figure 1]. Standard error for the total sample is \pm 0.29 . The equation derived for total sample can be used within the predictive range $\left(R^{2}\right)$ of \pm 0.9599 for right forearm length. Left forearm showed high positive value of correlation coefficient $(>0.9)$ which suggest a strong positive correlation between stature and left forearm length [Figure 2]. Standard error for the total sample is \pm 0.30 . The equation derived for total sample can be used within the predictive range $\left(R^{2}\right)$ of \pm 0.9752 for Left Forearm length. Regression equation for estimation of stature from right forearm length is $S=1.4111 \mathrm{Rt} F A L+$ 126.72, and from left forearm length is $S=1.3774 \mathbf{~ L t}$ FAL+ 128.39.

The observed linear correlation of the various parameters tabulated with Pearson's correlation coefficient value tabulated in table no. 04 .

Table 04: Correlations for whole sample size (Whole sample)

\begin{tabular}{|l|l|c|c|c|c|}
\hline \multicolumn{2}{|c|}{} & Stature & Right FAL & Left FAL & Average FAL \\
\hline \multirow{5}{*}{ Stature (S) } & Pearson Correlation & 1 & $.980^{* *}$ & $.988^{* *}$ & $.985^{* *}$ \\
\cline { 2 - 6 } & Sig. (2-tailed) & - & .000 & .000 & .000 \\
\cline { 2 - 7 } & $\mathrm{N}$ & 255 & 255 & 255 & 255 \\
\hline \multirow{5}{*}{ Right FAL } & Pearson Correlation & $.980^{* *}$ & 1 & $.994^{* *}$ & $.998^{* *}$ \\
\cline { 2 - 7 } & Sig. (2-tailed) & .000 & - & 250 & .000 \\
\cline { 2 - 6 } & $\mathrm{N}$ & 255 & 255 & 255 & 255 \\
\hline
\end{tabular}




\begin{tabular}{|l|l|c|c|c|c|}
\hline \multicolumn{2}{|c|}{} & Stature & Right FAL & Left FAL & Average FAL \\
\hline \multirow{4}{*}{ Left FAL } & Pearson Correlation & $.988^{* *}$ & $.994^{* *}$ & 1 & $.999^{* *}$ \\
\cline { 2 - 6 } & Sig. (2-tailed) & .000 & .000 & - & .000 \\
\cline { 2 - 6 } & $\mathrm{N}$ & 255 & 255 & 255 & 255 \\
\hline \multirow{4}{*}{ Average FAL } & Pearson Correlation & $.985^{* *}$ & $.998^{* *}$ & $.999^{* *}$ & 1 \\
\cline { 2 - 6 } & Sig. (2-tailed) & .000 & .000 & .000 & - \\
\cline { 2 - 6 } & $\mathrm{N}$ & 255 & 255 & 255 & 255 \\
\hline
\end{tabular}

**Correlation is significant at the 0.01 level (2-tailed).

Regressions are given in Tables indicates highly significant results for all regressions $(r>0.9 ; p<0.0001)$; $\mathrm{t}$-statistics for intercepts and slopes likewise display high significance in all cases. Correlations between stature to Right forearm length/left forearm length are very high for all and highly predictive with the left forearm measurements.

\section{Discussion}

In absence of whole body of individual, where the accurate, direct measurement for stature is not possible, other parameters are used to predict individual's stature as it is the most important and useful anthropometric parameter to establish the physical identity of an individual. ${ }^{2,4}$ Forearm length can be used to predict stature in mutilated remains involving part of upper limb of deceased person or in living subjects, if stature measurement not possible due to vertebral column deformity, bedridden, old or frail patients. ${ }^{5-7}$

In the present study, a total of 255 students between the age of 17 and 24 years were considered. As maximum height of an individual is attained between 17 and 24 years, these individuals were selected for the study. Many recent studies ${ }^{8,9,11,14-16}$ also enrolled subjectsof same age group.

In present study, we observed that the males have higher anthropometric measurement than that of females. ${ }^{8-11}$ These differences can be due to gender associated hormonal factors, genetic factors and lifestyle factors. Age of puberty being later in males and even the bony epiphyseal fusions are around two year later in males as compared to females leads to additional growth and increase in height. Inter and intra population variations were observed in relation to anthropometry due to factors such as genetic makeup, age, gender and ethnicity. ${ }^{9-14}$
In our study, mean right forearm length in male (28.9) was more than female (23.2), and mean left forearm length in male (28.5) was more than female (22.5). The differences were statistically significant $(P<0.001)$. So, the same regression equation can't be used in both sexes to estimate stature. We found strong correlation between stature and forearm length and it was similar to the previous studies. ${ }^{9,15,16}$ Chikhalkar et $\mathrm{al}^{9}$ showed that the highest degree of correlation $(\mathrm{r}=$ 0.6558 ) with forearm length followed by foot-length ( $\mathrm{r}$ $=0.6102$ ) of stature. Our study showed the comparable results with more strong correlation.

Ilayperumaet $\mathrm{al}^{14}$ conducted a study on 258 medical students (140 males and 118 females) of faculty of medicine, university of Ruhana, Galle, Srilanka in age range of 20-23 years with a mean value of stature in males and females was $170.14 \pm 5.22 \mathrm{~cm}$. The mean forearm length in Srilankan male and females was $27.56 \pm 1.30$ and $25.11 \pm 1.24 \mathrm{~cm}$ compared with Western Indian males and females was $28.5 \pm 4.17 \mathrm{~cm}$ and $22.5 \pm$ $4.2 \mathrm{~cm}$ respectively. The $\mathrm{r}$ vale values for Shrilankan males \& females were 0.66 and 0.76 respectively and 0.9843 and 0.9793 for Western Indians, respectively.

Nath et $\mathrm{al}^{15}$ conducted a research for reconstruction of stature using percutaneous length of forearm bones among the 199 Munda (110 males and 89 females) of Midnapur district, West Bengal in age group of 18-30 years. The mean value of stature in males was $156.19 \mathrm{~cm}$ whereas in Western Indian males it was $167.8 \mathrm{~cm}$. Similarly, the mean value of stature in Munda females was $148.64 \mathrm{~cm}$ whereas in Western Indian females were $159.4 \mathrm{~cm}$. The mean values offorearm length in Munda males and females was $24.60 \mathrm{~cm}$ and $22.85 \mathrm{~cm}$ respectively and in Western Indian males \& females were $28.5 \mathrm{~cm}$ and $22.5 \mathrm{~cm}$ for left forearm and $28.9 \mathrm{~cm}$ and $23.2 \mathrm{~cm}$ for right forearm, respectively. 
$2.2 \mathrm{~cm}$ and $26.56 \pm 15.01 \mathrm{~cm}$ respectively. The ' $\mathrm{r}$ ' value was 0.66 and 0.76 in Srilankan and 0.601 and 0.53 respectively for North Indians

The stature found by different authors ${ }^{5,8,9,14-16}$ in India in different region or state is different than the present study. Author from Chandigarh (North India) ${ }^{16}$ found mean (SD) stature of male was 168.2 (6.5) and offemale was 155 (5.2). These variations could be due to different genetic constitution, environmental factorsand nutrition in different population groups. ${ }^{15,16}$ In this study, students were enrolled which are from middleto higher socioeconomic class. So, the anthropometric measurements may be on higher side in comparison to the general population. A community based study to formulate regression equation for all population needed.

\section{Conclusion:}

Average Stature of male was $167.8( \pm 5.9) \mathrm{cm}$, and it was more than female $[159.4( \pm 5.9) \mathrm{cm}]$ with statistical significance. Similarly, right and left forearm lengths of male was more than that of female. We found correlation coefficient $(R)$ of 0.9699 in male and 0.9739 in female for stature using simple regression with right forearm and 0.9698 in male and 0.9843 in female for stature using simple regression with left forearm, which shows strong correlation between stature and forearm length. Stature can be accurately estimated from forearm length more precisely with left forearm length using simple regression equation.

We proposed that these regression equations presented by this study will help the task of stature estimation for adults in forensics to aids in identification in criminal investigation. Especially in endogamous populations, correlation coefficients for forearm lengths and stature are high, and thus applicable for identification in the forensic field. These population specific results may be applied in endogenous populations only.

\section{Conflict of Interests: None.}

\section{Source of Funding: None.}

\section{Ethical Clearance: Yes.}

Contributor-ship of authors: Data collection done by first author. All the authors contributed equally in conception, analysis and interpretation of the study as well drafting, revising the manuscript and approval of final version.

\section{References}

1. "Anthropometry". biologydictionary.net. Cited on 2020 May 21. Available from: https:// biologydictionary.net/anthropometry/

2. Mukherjee JB, editor. Forensic Medicine and Toxicology. 2nd ed. New Delhi: Arnold Associates; 1994. Personal identification; pp. 128-9.

3. Krishan K. Determinaton of stature from foot and its segments in a North Indian Populaton. Am J Forensic Med Pathol2008;29:297-303.

4. Akhlaghi M, Hajibeygi M, Zamani N, Moradi B. Estimation of stature from upper limb anthropometry in Iranian population. Journal of Forensic and Legal Medicine. 2012; 19(5):280-4.

5. Dongare SS, Deokar RB, Patil SS, Jadhav PL. Correlation of Stature to Arm Span and BiacromialShoulder Width in Young Adults of Western Indian Population. Int J Educ Res Health Sci 2017;3(2):64-70.

6. Lundy JK. The mathematical versus anatomical method of stature estimation from the long bones. Am J Forensic Med Pathol 1985;(6) No.1: 73- 76.

7. Madden AMT, Tsikoura T, Stott DJ. The estimation of body height from ulnar length in adults from different ethnic groups. J. Hum. Nutr. Diet. 2008; 21(4):394.

8. Potdar AB, Rathod P, Potdar PA, Desai MM. Indian Journal of Forensic Medicine \& Toxicology, 2019;13(2):219-21.

9. Chikhalkar BG, Mangaonkar AA, Nanandkar SD, Peddawad RG. Use measurement of long bones, hand and foot dimensions of local populaton of Mumbai. J Indian Acad Forensic Med 2009;32:32931.

10. Akhlaghi M, Sheikhazadi A, Ebrahimnia A, Hedayati M, Nazparvar B, Anary SHS. The value of radius bone in prediction of sex and height in the Iranian population. Journal of Forensic and Legal Medicine. 2012; 19(4):219-22.

11. Ahmed AA. Estimation of stature from the upper limb measurements of Sudanese adults. Forensic Science International. 2013; 228(1):178. e1- e7.

12. Varun R, Jayasinghearachchi TM, Priyalini R, Gunasena MD. Arm span and knee height as predictors of stature among Peradeniya medical students. Sri Lankan J Anaesthesiol. 2011;19:7680 . 
13. Ebite LE, Ozoko TC, Eweka AO, Otuaga PO, Oni AO, Om'Iniabohs FAE. Height: Ulna ratio: A method of stature estimation in a rural community in Edo state, Nigeria. The Internet Journal of Forensic Science 2008; 3(1).

14. IlayperumaI, Nanayakkara $G$ and Palahepitiya N. A model for the estimation of personal stature from the length of forearm. International Journal of Morphology 2010;28(4) 1081-1086.
15. Nath S, Duggal N and Chandra NS. Reconstruction of stature on the basis of percutaneous length of forearm bones among the Munda of Midnapur district. West Bengal Human Science 1998;37 170175.

16. Singh B, Kaur M, Kaur J, Singh M, Batra A. Estimation of stature from forearm length in north Indians: an anthropometric study. International Journal of Basic and Applied Medical Sciences. 2013; 3(1):201- 4 . 